\title{
No sacred cows as private sector embraces society-wide solutions
}

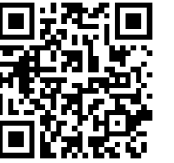

There were no sacred cows at October's Hospital Association of South Africa (HASA) conference - all the stark realities of our deeply economically divided society, its regulatory shortcomings and our inequitable healthcare delivery system were aired, and some solutions offered.

That is how both HASA's chairperson, Melanie da Costa, and one of the world's leading healthcare economics and policy consultants, Dr Margaret Guerin-Calvert, President of the US-based Center for Healthcare Economics and Policy, summed up the conference.

Guerin-Calvert, who chaired a debate on 'Extracting efficiencies in the healthcare sector', said what impressed her most was the incredible commitment to access and quality of care' shown by a cross-section of participants determined to tackle fragmentation in the public and private sectors. Several perspectives were shared on the importance of 'figuring out' integrated systems, improving the alignment of incentives and better co-ordinated care, with much emphasis on the private sector working with the public sector to craft solutions. One persistent theme was the need for a private sector that can serve more public sector patients, creating an altogether more robust system. 'I thought people [at the conference] went out on a limb: physicians were trying to look at relative costs and all available data was put forward, at least taking some issues off the table,' she added.

Da Costa said a highlight of the conference was watching Dr Brigid Strachan, a top government and private sector consultant on healthcare financing and human resources for health, lay out the latest data on the current and projected shortage crisis in specialists - which was then thoroughly debated by some of the country's top experts.

\section{'Sacrifice ideology for common purpose - Netcare's Friedland}

'I also liked what Dr Richard Friedland [CEO of Netcare] said about the sacrifice of ideology for common purpose,' said $\mathrm{Da}$ Costa. 'I think that's critical if a national health insurance (NHI) is to succeed. He's leading the way with hugely successful

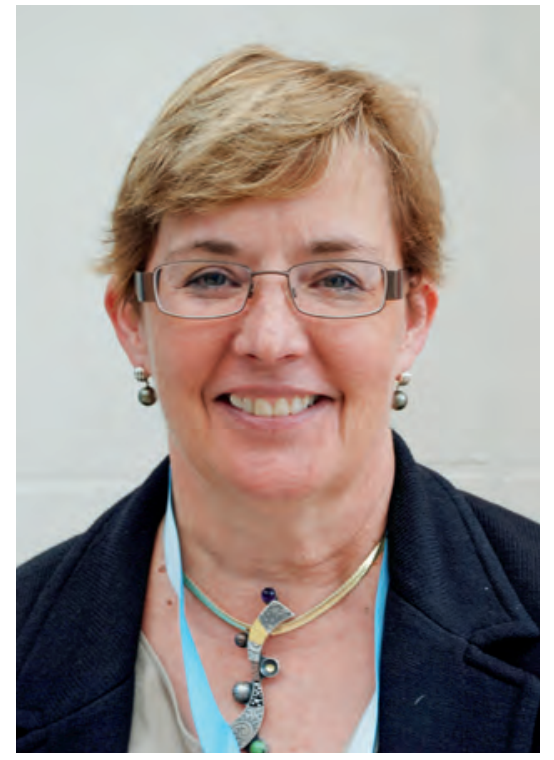

Dr Margaret Geurin-Calvert, President of the Center for Healthcare Economics and Policy. Pictures: Chris Bateman

public/private hospitals in Lesotho and the United Kingdom.'

She pointed out that governance structures within the state health system are 'crippling delivery at ground level' with emasculated hospital managers unable to directly fire staff or order drugs. 'We've tied the hands of those at ground level to do their job with very complex governance organograms and reporting structures,' she added. Da Costa revealed that the National Department of Health's newly formed Academy for Leadership and Management in Health Care, led by former University of Cape Town Dean of Health Sciences Professor Marian Jacobs, had consulted HASA in preparing for its first hospital-CEO training programme.

'They steered us a bit into coding and diagnostic related groupings, but Richard [Friedland] said the first thing a hospital manager needs to know in the morning is whether his staff have arrived. They were trying to solve the higher-grade problems, the luxury, easy ones - but we have to deal with the $20 \%$ that will give us the $80 \%$ benefit! Like investing in a fingerprinting system to rule out people clocking in for their friends. You'd be surprised to find out just who spends a lot of time at work and who doesn't. Outside of drugs and surgicals, $60-70 \%$ of operating costs are for nursing or payrolls. Doing something as simple as that can save you money and improve the quality of care. If you want to know now to make a hotdog, go and speak to somebody who makes hotdogs!' she quipped.

Da Costa said the academy was startled by Friedland's direct and uncomplicated input, 'but that's a prime example of why public/ private sector dialogue is so important'. She added that her ambition for next year is to include more public sector players to sit on all the HASA conference discussion panels. This year, National Health Minister Dr Aaron Motsoaledi addressed the conference, while Dr Terence Carter, Deputy Director-General: Hospitals Tertiary Service and Workforce Management, took part in Strachan's panel debate.

Da Costa was upbeat about the NHI's prospects - if more joint-policy planning and pragmatic implementation between the two sectors can be achieved. She gave the example of an actuarial study showing a 19\% cost saving via mandatory cover and a risk equalisation fund. She said this meant that, of the R100 billion in medical aid contributions generated annually in South Africa, the resultant near-R20 billion saving could conceivably be funnelled into a 'government aid' programme. 'I mean, Discovery's [member] contributions are R30 billion for some 2.5 million beneficiaries - imagine what you could realise with another R20 billion!'

\section{An added attraction of the Lesotho project was that the consortium can directly employ doctors, something disallowed in South Africa.}

She said such a fund could enable everyone on social grants to see a GP, with money over for medications and the use of a private hospital's emergency unit. The public sector could be used for the remainder of their needs. The government's sudden change from a social health insurance scheme to NHI (following the ANC's Polokwane conference) and the now-truncated medical scheme regulation (side-stepping risk equalisation and mandatory cover) was the equivalent of 'throwing the baby out with the 


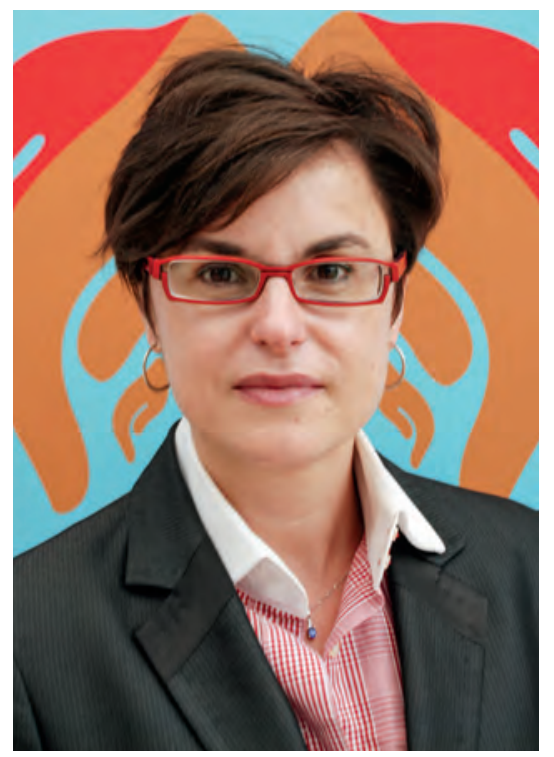

Melanie da Costa, CEO of HASA.

bathwater; it's like stopping halfway through a pregnancy - you look fat and funny'.

\section{Delivery model should manage complete pathways of care}

Friedland told delegates that a wider social compact between the public and private sectors to create a more equal and effective healthcare system is essential - but that this will mean letting go of the distrust and ideology that currently cloud the debate on both sides.

'The government needs to acknowledge that it alone cannot provide the panacea for healthcare in South Africa', he said. 'The private sector needs to acknowledge and embrace the willingness to treat public sector patients on an equal basis ... we need a plurality of providers, giving universal coverage to all South Africans.' This would require a different delivery model, which allows providers to manage the complete pathways of care (as opposed to the fragmented, unco-ordinated manner in which primary, tertiary and follow-up care is currently administered). He backed the growing call for mandatory health insurance for all formally employed people earning above the tax threshold (about $30 \%$ of the population, v. the $17 \%$ now covered). Elements of the proposed NHI are 'immediately achievable - we can't wait 14 years to achieve what must be an absolute non-negotiable tenet of our society - universal health care for all'.

\section{Learning from Lesotho}

Friedland said that in the hills above Maseru, Lesotho, the former Queen Elizabeth II Hospital, now called the Mamahato Memorial Hospital, situated in one of the poorest areas of southern Africa, had been transformed into a public/private state-ofthe-art tertiary referral hospital, coming well within the government's health budget. The 425-bed public hospital and three primary care referral clinics, serving more than 1.8 million people, are now managed by the private Tsepong Constortium, of which Netcare is a $40 \%$ shareholder. Lesotho has one of the world's highest per capita incidences of TB (632/100 000) while the 2012 HIV/ AIDS estimates showed a prevalence of $26 \%$.

In February this year the World Bank commissioned an independent study by Boston University to evaluate outcomes. They found a $41 \%$ reduction in the death rate, a $21 \%$ reduction in maternal mortality and a $65 \%$ reduction in the paediatric pneumonia death rate. This is in spite of a $51 \%$ increase in hospital admissions and outpatient visits surging to $126 \%$. The hospital did not previously have the capacity to handle low-birth-weight infants but now boasts a $100 \%$ survival rate for infants under 1500 g, Friedland added.

'Imagine if we had 50 of these in South Africa, how we could transform the delivery of healthcare', he urged. Quizzed on why the partnership was piloted in Lesotho and not South Africa, Friedland said it was 'merely a question of the government at the time being willing to work with us'.

Elaborating, he said South Africa has yet to put out tenders for clinical services, although private healthcare corporates do have SA public sector facility management contracts, including Netcare's contracts in Bloemfontein, Grahamstown and Port
Alfred. An added attraction of the Lesotho project was that the consortium can directly employ doctors, something disallowed in South Africa.

A total of R1.2 billion capital expenditure was required for the hospital and its clinics. The Lesotho government put in R400 million, while the consortium borrowed R800 million from the Development Bank of South Africa. Operational costs are calculated against the Lesotho Department of Health's budget with a consumer price index (CPI) annual increment. Friedland said returns are being calculated over a 20 -year-plus period.

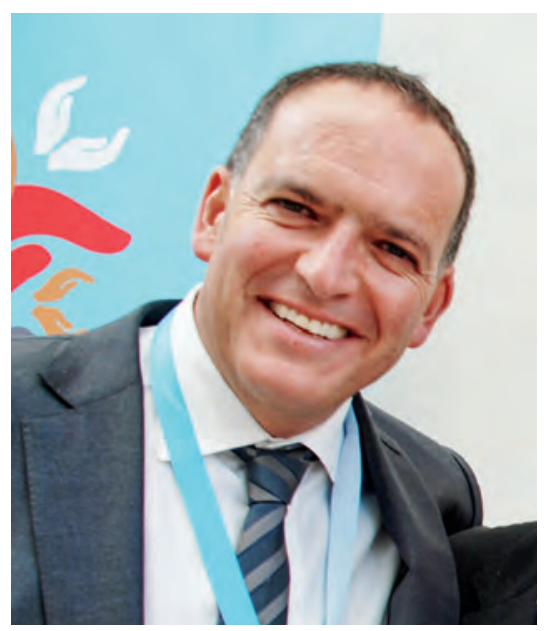

Dr Richard Friedland, Netcare's CEO.

In the United Kingdom, Netcare provides clinical services on a 'very large' scale, having grown its National Health Service patient base from 3\% to $33 \%$ since 2006 . 'Our bona fides in terms of publicly funded work are established and we'd be happy to do that in South Africa, said Friedland. 'We have enormous capacity and capability within the sector which we should be galvanising, and [which] the government should be using to improve outcomes and reduce waiting lists.'

\section{Chris Bateman}

chrisb@hmpg.co.za

S Afr Med J 2014;104(1):6-7.

DOI:10.7196/SAMJ.7802 